\title{
Sex Differences in Care Need and Survival in Patients Admitted to Nursing Home Poststroke
}

\author{
Amy Y. X. Yu®i, Laura C. Maclagan, Christina Diong, Peter C. Austin, \\ Moira K. Kapral Di, Richard H. Swartz, Susan E. Bronskill
}

ABSTRACT: Background: Women are more likely to be admitted to nursing home after stroke than men. Differences in patient characteristics and outcomes by sex after institutionalization are less understood. We examined sex differences in the characteristics and care needs of patients admitted to nursing home following stroke and their subsequent survival. Methods: We identified patients with stroke newly admitted to nursing home between April 2011 and March 2016 in Ontario, Canada, with follow-up until March 2018 using linked administrative data. We calculated prevalence ratios and 95\% confidence intervals (CIs) for the primary outcomes of dependence for activities of daily living, cognitive impairment, frailty, health instability, and symptoms of depression or pain, comparing women to men. The secondary outcome was all-cause mortality. Results: Among 4831 patients, 60.9\% were women. Compared to men, women were older (median age [interquartile range, IQR]: 84 [78, 89] vs. $80[71,86]$ ), more likely to be frail (prevalence ratio 1.14, 95\% CI [1.08, 1.19]), have unstable health $(1.45[1.28,1.66])$, and experience symptoms of depression $(1.25[1.11,1.40])$ or pain $(1.21[1.13,1.30])$, and less likely to have aggressive behaviors $(0.87$ [0.80, 0.94]). Overall median survival was 2.9 years. In a propensity-score-matched cohort, women had lower mortality than men (hazard ratio $0.85,95 \%$ CI $[0.77,0.94]$ ), but in the age-stratified survival analysis, the survival advantage in women was limited to those aged 75 years and older. Conclusions: Despite lower subsequent mortality, women admitted to nursing home after stroke required more care than men. Pain and depression are two treatable symptoms that disproportionately affect women.

RÉSUMÉ: Différences entre les sexes en matière de besoins en soins et de taux de survie dans le cas de patients admis dans des foyers de soins en longue durée à la suite d'un AVC. Contexte : Les femmes sont plus susceptibles que les hommes d'être admises dans des foyers de soins en longue durée (nursing homes) à la suite d'un AVC. Ceci dit, une fois ces patients institutionnalisés, on comprend encore mal les différences entre les sexes en ce qui concerne leurs caractéristiques et l'évolution de leur état de santé. Nous avons ainsi analysé ces différences, tant en ce qui concerne les caractéristiques des patients que leurs besoins en soins, après qu'ils ont été admis dans des foyers de soins en longue durée à la suite d'un AVC auquel ils ont survécu. Méthodes : C'est en utilisant des données administratives associées que nous avons identifié des patients ontariens victimes d'AVC et nouvellement admis entre avril 2001 et mars 2016, patients ayant fait l'objet d'un suivi jusqu'en mars 2018. Dans le but de comparer les femmes aux hommes, nous avons calculé les taux de prévalence (IC $95 \%$ ) en mettant l'accent sur les aspects suivants : dépendance à l'égard d'autrui en ce qui a trait aux activités du quotidien, atteinte cognitive, fragilité et instabilité de l'état de santé, symptômes de dépression et manifestations de douleur. De façon secondaire, nous nous sommes également penchés sur les taux de mortalité toutes causes confondues. Résultats : Parmi les 4831 patients, 60,9\% étaient des femmes. Comparées aux hommes, ces dernières étaient plus âgées (âge médian [EI] : 84 [78,89] contre 80 [71,86]) et plus susceptibles d'être considérées « fragiles » (taux de prévalence 1,14; IC $95 \%$ [1,08 - 1,19]), d'avoir une santé instable $(1,45$ [1,28 - 1,66]), de présenter des symptômes de dépression $(1,25[1,11-1,40])$ et des manifestations de douleur $(1,21[1,13-1,30])$. Ajoutons aussi que les femmes étaient moins susceptibles d'avoir des comportements agressifs $(0,87$ [0,80 - 0,94]). De façon générale, le taux médian de survie de ces patients a été de 2,9 années. À l'aide de la méthode d'appariement de cohortes en fonction de scores de propension (propensity score matched cohort), il s'est avéré que les femmes avaient un taux de mortalité inférieur à celui des hommes (rapport de risque 0,85 ; IC $95 \%$ [0,77 - 0,94]). Toutefois, lors d'une analyse des taux de survie stratifiés selon l'âge, l'avantage des femmes en termes de survie a été limité à celles âgées de plus de 75 ans. Conclusions : En dépit de taux de mortalité inférieurs à la suite d'un AVC, il a été démontré que les femmes admises en foyers de soins en longue durée vont avoir besoin de plus de soins si on les compare aux hommes. À cet égard, la douleur et la dépression sont deux symptômes traitables qui les affectent de façon disproportionnée.

Keywords: Stroke, Women, Nursing home, Mortality, Health services research

doi:10.1017/cjn.2019.335

Can J Neurol Sci. 2020; 47: 153-159

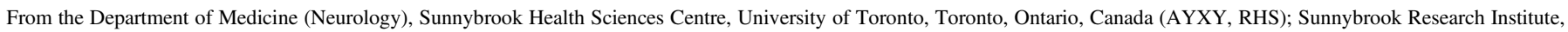

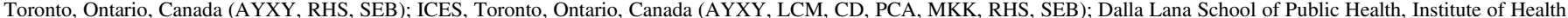

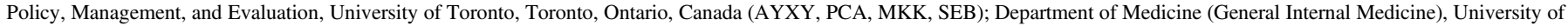
Toronto-University Health Network, Toronto, Ontario, Canada (MKK)

Received October 1, 2019. Final Revisions Submitted November 14, 2019. Date of Acceptance November 26, 2019.

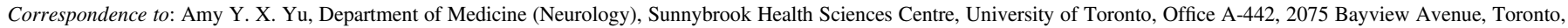

Ontario, M4N 3M5, Canada. Email: amyyx.yu@utoronto.ca 


\section{INTRODUCTION}

Admission to nursing home is a frequent surrogate for poor outcome in stroke research, but a more fulsome characterization of patients after institutionalization is lacking. ${ }^{1,2}$ Further, sex differences in patient characteristics and care needs at entry to nursing home following stroke and subsequent survival are not well understood, ${ }^{2-4}$ but quantifying these potential differences may help to improve and individualize care after stroke.

Women are more likely than men to be admitted to nursing home following a stroke. ${ }^{2-5}$ Women tend to be older than men at the time of their first stroke and present with more severe strokes, which may explain some of the difference in nursing home admissions. ${ }^{2,6,7}$ However, there may be other contributing factors. Living alone or without a spouse is associated with an increased need for nursing home placement after stroke, and some studies suggest that increased levels of social support may delay institutionalization. ${ }^{6,8,9}$ In stroke populations, women are more prone to social isolation than men because they are older, less likely to be married, and more likely to be living alone. ${ }^{2,10}$ It is not clear if women are more likely to be institutionalized than men after stroke because they are more functionally disabled poststroke or if women are more likely than men to lack sufficient social support to enable their return to the community. If women are observed to have fewer care needs than men at admission to nursing home after stroke and lower mortality, interventions to promote community reintegration may be needed.

We aimed to determine whether sex differences exist in the characteristics, care needs, and survival of new nursing home residents admitted after stroke. We hypothesized that women may have fewer care needs and lower mortality than men and that they may be older, less likely to be married, and more likely to be living alone prior to nursing home admission.

\section{Methods}

We used linked population-based administrative and clinical data to identify adult patients (aged 18-110 years) discharged alive from an acute care hospital following stroke between April 1, 2011 and March 31, 2016, and who were subsequently admitted to a nursing home within 180 days. Patients with ischemic stroke and intracerebral hemorrhage were identified using the International Classification of Diseases 10th Revisions (ICD-10) codes H34.1, I63.x, I64.x, and I61.x coded as the most responsible diagnosis. ${ }^{11}$ Patients were followed until March 31, 2018. We excluded patients who were not residents of Ontario, those without a valid health insurance number, patients living in a nursing home prior to stroke, as well as those with any stroke events occurring in-hospital during an admission for a different health condition.

Health administrative datasets (Supplementary Table S1) were linked using unique encoded identifiers and analyzed at ICES. We used the Resident Assessment Instrument-Minimum Data Set version 2.0 (RAI-MDS 2.0) to determine care needs upon admission to nursing home. Patients without a RAI-MDS 2.0 assessment within 14 days of admission to a nursing home were excluded. These databases have been used extensively in health services research. ${ }^{12}$
The primary outcomes were care needs measured using validated clinical and functional scales in the RAI-MDS 2.0, including the Activities of Daily Living Hierarchy Scale (a 6-point scale with scores $\geq 3$ indicating total dependence requiring extensive supervision), the Depression Rating Scale (a 14-point scale with scores $\geq 3$ indicating the presence of depressive disorder symptoms), the Cognitive Performance Scale (a 6-point scale with scores $\geq 2$ indicating the presence of cognitive impairment), the Aggressive Behaviour Scale (12-point scale with scores $\geq 1$ indicating the presence of aggression), the Pain Scale (a 3-point scale with scores $\geq 1$ indicating the presence of pain), the Index of Social Engagement (a 6-point scale with scores $<6$ indicating lower levels of engagement), the Changes in Health, End-stage Disease, and Signs and Symptoms Scale (5-point with scores $\geq 2$ indicating health instability and risk of poor outcomes). ${ }^{13-17}$ Frailty status was assessed using a 72-item index derived using a cumulative deficits approach from items in the RAI-MDS 2.0 and categorized as $0.0-0.3=$ non-frail or pre-frail versus $>0.3=$ frail. $^{17,18}$ The secondary outcome of all-cause mortality was assessed following nursing home admission until March 31, 2018. The use of data in this project was authorized under section 45 of Ontario's Personal Health Information Protection Act.

\section{Statistical Methods}

Patient characteristics were described by sex using proportions for categorical variables and medians and interquartile ranges (IQRs) for continuous variables. We calculated unadjusted prevalence ratios and associated $95 \%$ confidence intervals (CIs) for care needs comparing women to men in all patients admitted to a nursing home following stroke discharge. These estimates were also stratified by age (categorized as 18-64, 65-74, 75-84, and over 85 years), marital status (categorized as married vs. not married, including patients who were never married, widowed, separated, divorced, and unknown status), and baseline living situation (living alone vs. not).

We investigated sex differences in all-cause mortality after admission to nursing home by plotting Kaplan-Meier survival estimates in men and women and comparing them using the logrank test. Survival curves were plotted for the overall cohort and stratified by age. We used propensity score matching to account for differences in characteristics at admission to nursing home between men and women. ${ }^{19}$ The propensity score was estimated using a logistic regression model, in which sex was regressed on all measured baseline covariates, including sociodemographic characteristics, comorbidities, care needs, and care trajectories, including whether the patient had been admitted to inpatient rehabilitation, complex continuing care, readmitted to acute care, or utilized home care services between discharge from acute care and admission to nursing home. Men and women were matched on age ( \pm 2 years) and the logit of the propensity score, using calipers equal to 0.2 of the standard deviation of the logit of the propensity score. ${ }^{20}$ Characteristics of men and women before and after matching were compared using standardized differences. ${ }^{21}$ Standardized differences of $<0.1$ were used to indicate adequate balance. The rate of all-cause mortality was compared between men and women in the matched sample using a Cox proportionalhazards regression model in which the hazard of all-cause death 
was regressed on sex. Each individual was followed from nursing home admission until death or the end of the study period on March 31, 2018 (at which point they were censored), whichever came first. A robust variance estimator was used to account for the matched nature of the sample. ${ }^{22}$ All analyses were performed using SAS version 9.4 (SAS Institute Inc., Cary, NC, USA).

\section{Results}

Among 54,545 patients discharged alive after stroke, 4853 were newly admitted to nursing home within 180 days. After excluding patients who were nonresidents of Ontario $(n=6)$ and those who did not have a full RAI-MDS 2.0 assessment within 14 days of admission to nursing home $(n=16)$, analyses were performed on $4831(8.9 \%)$ patients, of whom $60.9 \%$ were women. Table 1 shows the baseline characteristics of the cohort by sex. Compared to men, women were older (median age [IQR]: 84 years [78, 89] for women vs. $80[71,86]$ years for men), less likely to be married ( $21.9 \%$ women vs. $50.4 \%$ men), and more likely to live alone at baseline (20.8\% women vs. $16.9 \%$ men). Sex differences in care trajectories between discharge from acute care and admission to nursing home are shown in Supplementary Table S2.

At nursing home admission, women were more likely than men to be frail $(62.1 \%$ women vs. $53.7 \%$ men), have unstable health $(21.3 \%$ women vs. $14.7 \%$ men $)$, experience symptoms of depression (22.8\% women vs. $18.3 \%$ men) and pain $(48.4 \%$ women vs. $39.9 \%$ men, Table 2 ). Women were less likely than men to exhibit aggressive behaviors $(31.3 \%$ women vs. $35.9 \%$ men). The prevalence ratios and $95 \% \mathrm{CI}$ for care needs comparing women to men for the overall cohort are shown in Figure 1, and stratified analyses by age, marital status, and baseline living situation are shown in Supplementary Table S3.

The median follow-up time was 2.33 years (IQR: 0.98, 3.73) for women and 2.31 years (IQR: $0.91,3.73$ ) for men. The overall median survival following nursing home admission was 2.9 years, $95 \%$ CI $(2.7,3.1)$. In the unadjusted age-stratified analyses, there was no sex difference in the Kaplan-Meier survival analysis among patients younger than 75 years of age, but women had lower mortality than men among those aged 75 years or older (Figure 2).

Following propensity score matching, 1364 pairs were matched (Supplementary Table S4) and included $46.3 \%$ of women and $72.4 \%$ of men in the original cohort. Men and women were well balanced in their baseline characteristics, care needs, and health care utilization, except for the length of stay in inpatient rehabilitation (median days [IQR]: 47 [31, 65] women vs. 50 [34, 72] men). In the propensity-score-matched analysis, women had a lower hazard of mortality compared to men (hazard ratio 0.85 and 95\% CI [0.77, 0.94], $p<0.001$, Figure 3).

\section{Discussion}

The majority of stroke survivors newly admitted to nursing home were women. Compared to men, women were more likely to be living alone prior to their stroke and less likely to be married. Women had lower mortality than men over time, but they had more care needs. Our results suggest that simply evaluating the need for nursing home admission as a surrogate for poor outcome without understanding the care needs at
Table 1: Baseline characteristics of patients with stroke newly admitted to nursing homes by $\operatorname{sex}(n=4831)$

\begin{tabular}{|c|c|c|c|}
\hline \multirow{2}{*}{ Baseline characteristics } & Women & Men & \multirow{2}{*}{ S-Diff } \\
\hline & $n=2946$ & $n=1885$ & \\
\hline \multicolumn{4}{|l|}{ Age categories (years) } \\
\hline $18-64$ & $154(5.2 \%)$ & $271(14.4 \%)$ & 0.31 \\
\hline $65-74$ & $332(11.3 \%)$ & $386(20.5 \%)$ & 0.25 \\
\hline $75-84$ & $1032(35.0 \%)$ & $667(35.4 \%)$ & 0.01 \\
\hline $85+$ & $1428(48.5 \%)$ & $561(29.8 \%)$ & 0.39 \\
\hline \multicolumn{4}{|l|}{ Marital status } \\
\hline Married & $646(21.9 \%)$ & $950(50.4 \%)$ & 0.62 \\
\hline Not married ${ }^{\mathrm{a}}$ & $2300(78.1 \%)$ & $935(49.6 \%)$ & 0.62 \\
\hline \multicolumn{4}{|c|}{ Living situation prior to nursing home admission } \\
\hline Living alone & $613(20.8 \%)$ & $318(16.9 \%)$ & 0.12 \\
\hline Not living alone & $2161(73.4 \%)$ & $1480(78.5 \%)$ & 0.12 \\
\hline \multicolumn{4}{|l|}{ Baseline home location } \\
\hline Small town $(<10,000)$ & $364(12.4 \%)$ & $272(14.4 \%)$ & 0.06 \\
\hline $\begin{array}{l}\text { Medium urban } \\
(10,000-100,000)\end{array}$ & $346(11.7 \%)$ & $235(12.5 \%)$ & 0.02 \\
\hline Large urban $(>100,000)$ & $2236(75.9 \%)$ & $1377(73.1 \%)$ & 0.07 \\
\hline \multicolumn{4}{|c|}{ Neighborhood income quintile } \\
\hline $1=$ Lowest & $681(23.2 \%)$ & $469(25.0 \%)$ & 0.04 \\
\hline $2=$ Next to lowest & $607(20.7 \%)$ & $388(20.7 \%)$ & 0 \\
\hline $3=$ Middle & $609(20.8 \%)$ & $368(19.6 \%)$ & 0.03 \\
\hline $4=$ Next to highest & $512(17.5 \%)$ & $343(18.3 \%)$ & 0.02 \\
\hline $5=$ Highest & $523(17.8 \%)$ & $305(16.3 \%)$ & 0.04 \\
\hline Diabetes & $1145(38.9 \%)$ & $854(45.3 \%)$ & 0.13 \\
\hline Hypertension & $2790(94.7 \%)$ & $1693(89.8 \%)$ & 0.18 \\
\hline Prior stroke & $402(13.6 \%)$ & $354(18.8 \%)$ & 0.14 \\
\hline Atrial fibrillation & $1264(42.9 \%)$ & $665(35.3 \%)$ & 0.16 \\
\hline Ischemic heart disease & $847(28.8 \%)$ & $648(34.4 \%)$ & 0.12 \\
\hline COPD & $799(27.1 \%)$ & $597(31.7 \%)$ & 0.1 \\
\hline Congestive heart failure & $858(29.1 \%)$ & $471(25.0 \%)$ & 0.09 \\
\hline Dementia & $1204(40.9 \%)$ & $747(39.6 \%)$ & 0.03 \\
\hline \multicolumn{4}{|l|}{ Charlson score categories } \\
\hline 0 & $547(18.6 \%)$ & $251(13.3 \%)$ & 0.14 \\
\hline 1 & $467(15.9 \%)$ & $256(13.6 \%)$ & 0.06 \\
\hline 2 & $683(23.2 \%)$ & $402(21.3 \%)$ & 0.04 \\
\hline $3+$ & $1249(42.4 \%)$ & $976(51.8 \%)$ & 0.19 \\
\hline Ischemic stroke & $2597(88.2 \%)$ & $1624(86.2 \%)$ & 0.06 \\
\hline Hemorrhagic stroke & $349(11.8 \%)$ & $261(13.8 \%)$ & 0.06 \\
\hline
\end{tabular}

$\mathrm{IQR}=$ interquartile range; $\mathrm{SD}=$ standard deviation; S-Diff $=$ standardized differences; $\mathrm{COPD}=$ Chronic Obstructive Pulmonary Disease. Standardized differences of $<0.1$ indicate adequate balance.

${ }^{a}$ Includes patients who were widowed, divorced, separated, never married, and unknown status.

admission or the subsequent survival incompletely captures the experience of the most severely disabled stroke survivors and may particularly underestimate the burden of stroke on women. 
Table 2: Health services care needs at nursing home admission by $\operatorname{sex}(n=4831)$

\begin{tabular}{l|c|c|c}
\hline \multirow{2}{*}{ Health services care needs } & Women & Men & \multirow{2}{*}{ S-Diff } \\
\cline { 2 - 4 } $\begin{array}{l}\text { Extensive supervision for activities } \\
\text { of daily living }\end{array}$ & $\mathbf{n = 2 9 4 6}$ & $1523(82.7 \%)$ & 0.08 \\
\hline Presence of symptoms of depression & $655(22.8 \%)$ & $336(18.3 \%)$ & 0.11 \\
\hline Presence of cognitive impairment & $2150(74.8 \%)$ & $1330(72.2 \%)$ & 0.06 \\
\hline Presence of aggressive behavior & $899(31.3 \%)$ & $661(35.9 \%)$ & 0.1 \\
\hline Lower social engagement & $2389(83.1 \%)$ & $1542(83.8 \%)$ & 0.02 \\
\hline Presence of pain & $1391(48.4 \%)$ & $735(39.9 \%)$ & 0.17 \\
\hline Instability in health status & $613(21.3 \%)$ & $270(14.7 \%)$ & 0.17 \\
\hline Frail & $1830(62.1 \%)$ & $1031(54.7 \%)$ & 0.15 \\
\hline
\end{tabular}

S-Diff $=$ standardized differences.

Standardized differences of $<0.1$ indicate adequate balance.

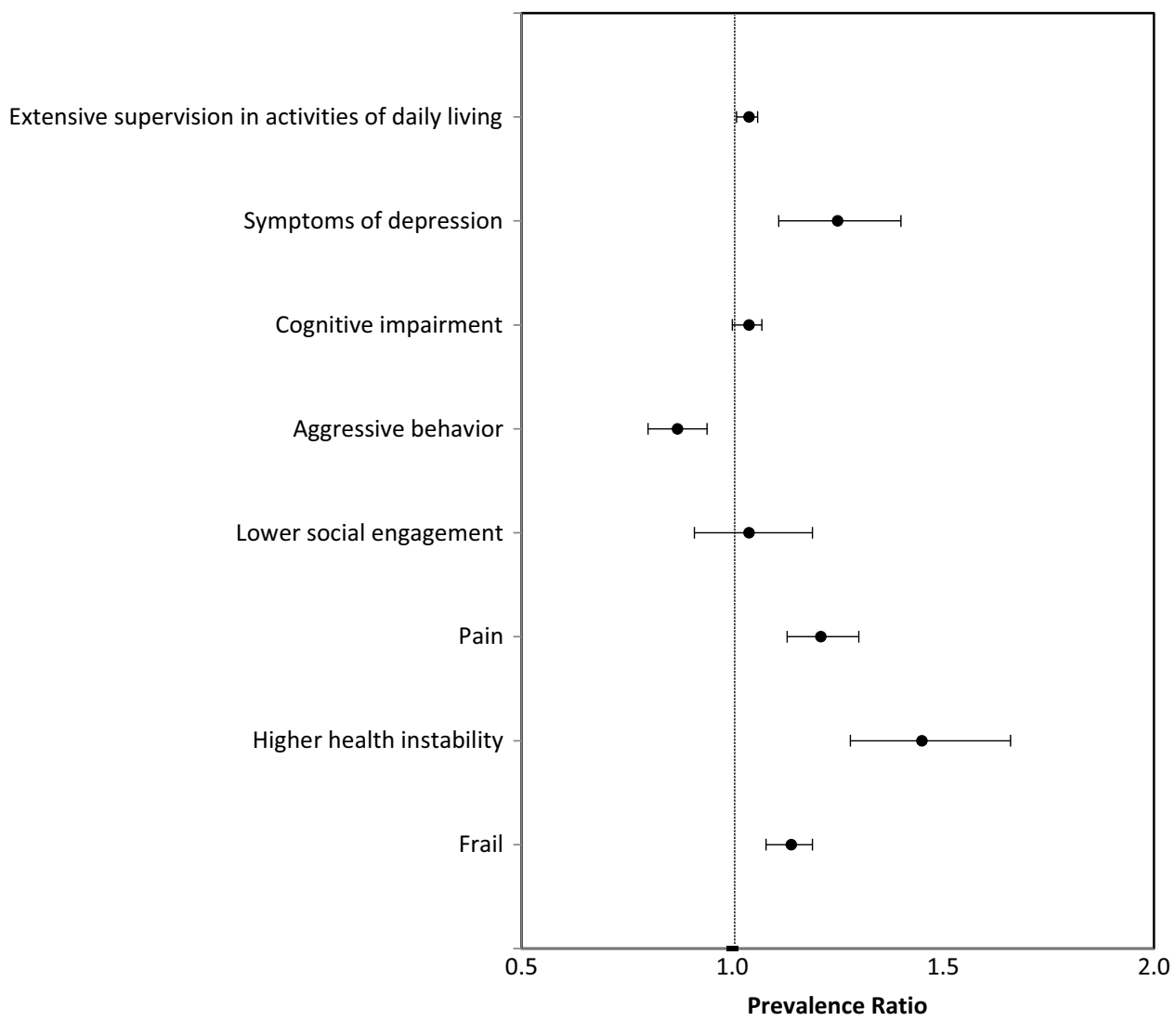

Figure 1: Prevalence ratios of care needs among newly admitted nursing home residents with stroke in Ontario, Canada, comparing women to men $(n=4831)$.

Sex differences in stroke care delivery have been previously described and span issues of prevention, access, and outcomes. For example, women with atrial fibrillation are less likely to receive oral anticoagulation or more likely to be treated with conservative doses compared to men, ${ }^{23,24}$ women with minor strokes are at higher risk of misdiagnosis ${ }^{25}$ and those with severe strokes are less likely to be treated with intravenous thrombolysis despite similar eligibility criteria. ${ }^{26,27}$ Whether closing these gaps in stroke care can decrease the number of women requiring nursing home or reduce their care needs at nursing home admission deserves dedicated evaluation.

Quantifying sex differences in the care needs at admission to nursing home may help identify opportunities to improve care. Consistent with prior reports, we found that women were more likely than men to report symptoms of pain and depression, two 
(A)

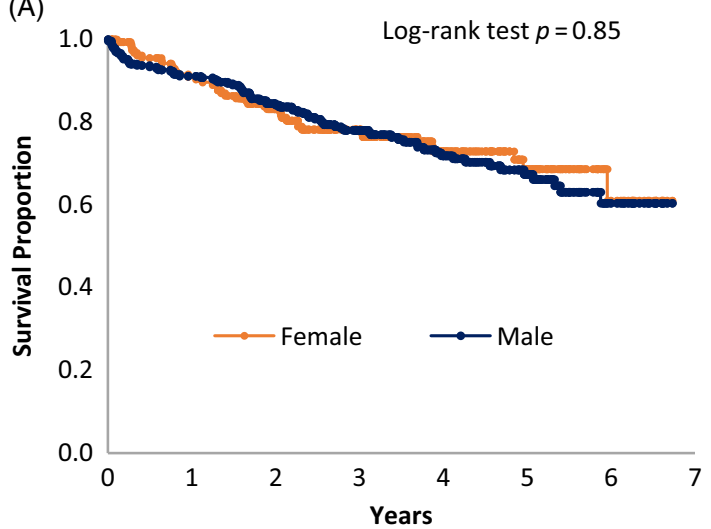

(C)

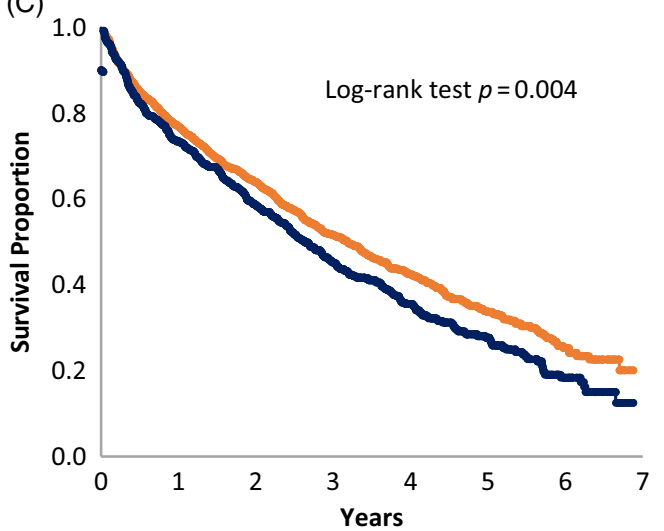

(B)

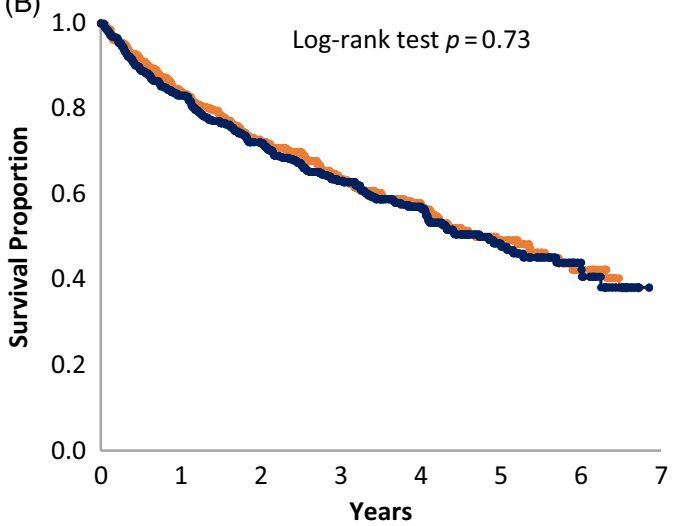

(D)

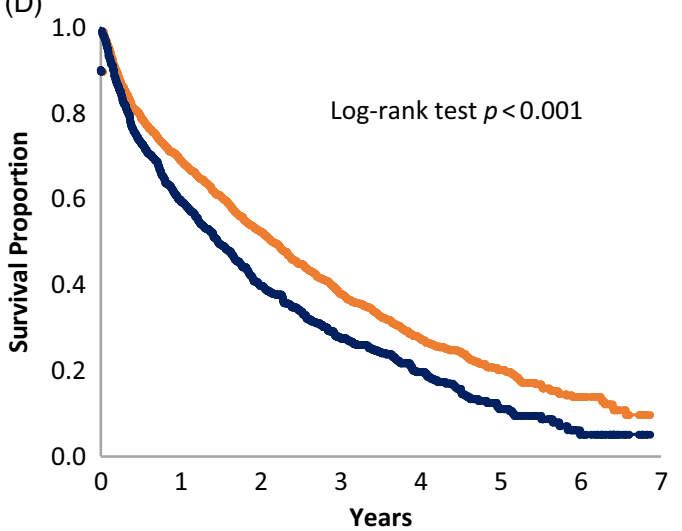

Figure 2: Age-stratified Kaplan-Meier survival curves of men and women with stroke after admission to nursing home $(n=4831)$.

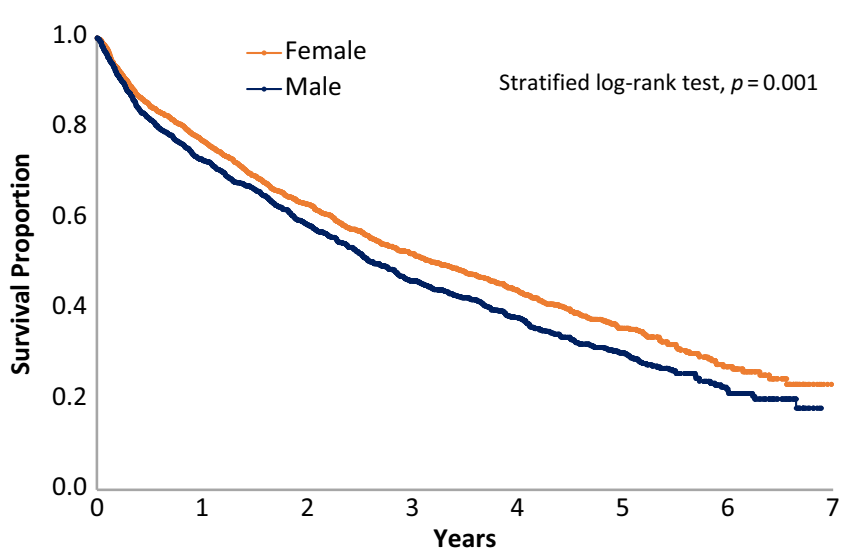

Figure 3: Survival following nursing home admission in propensityscore-matched cohort of men and women with stroke ( $n=1364$ pairs).

potentially treated symptoms. ${ }^{28,29}$ Pain after stroke can be related to musculoskeletal conditions, neuropathic in nature, as well as due to complications of immobility, such as pressure ulcers or reflex sympathetic dystrophy. ${ }^{30}$ Symptoms of depression after stroke are associated with the severity of disability and pain, and may be potentially influenced by patient preferences for end-oflife care, which may differ in men and women. ${ }^{31}$ Understanding why women are more likely to experience these symptoms in nursing home than men may help tailor treatments to individual needs and improve quality of life.

We found that women had decreased mortality over time compared to men in the propensity-score-matched cohort. The survival advantage in women has been also reported in residents admitted to nursing home for non-stroke conditions. ${ }^{32,33}$ However, only $46.3 \%$ of the women in the total cohort were matched to men. The age-stratified survival curves indicated that only women aged 75 years and older had lower mortality than men.

An important strength of the current study is the use of a population-based patient sample in the setting of a universal health care system with mandatory reporting of health services and standardized clinical assessments in nursing home. Our study nevertheless had several limitations. We were not able to determine advanced care directives, which are important for understanding long-term survival and may be different for men and women. ${ }^{31} \mathrm{We}$ did not have information on caregiver supports in the community, race/ethnicity, stroke severity, stroke etiology, or quality of life measures, as these are not available in administrative data. ${ }^{34}$ While financial incentives may motivate the overestimation of care needs, we do not think that any potential misclassification of care needs would differentially affect men or women. ${ }^{35}$ Finally, we were only able to examine baseline differences after admission to nursing home and did not have data on subsequent treatment or interventions once admitted. We also acknowledge that there are other important care needs in nursing home, such as pressure 
ulcers or malnutrition, that we have not included in the current study. Instead, we used validated composite scores that have shown to be predictive of clinical outcomes, such as a 72-item frailty index, which incorporates many aspects of resident care needs.

\section{Conclusion}

More women than men were newly admitted to nursing home after stroke and they had higher care needs despite lower mortality. We identified pain and depression as two potentially treatable symptoms that disproportionately affect women. Residents newly admitted to nursing home following stroke survive for a substantial length of time. Improving the care and quality of life of nursing home residents with stroke is an important subject of future study.

\section{ACKNOWLEDGMents}

This research was conducted with support from the Ontario Neurodegenerative Disease Research Initiative through the Ontario Brain Institute, an independent nonprofit corporation, funded partially by the Ontario government. ICES is funded by an annual grant from the Ontario Ministry of Health and Long-Term Care (MOHLTC). Parts of this material are based on data and information compiled and provided by the Canadian Institute for Health Information (CIHI). The opinions, results, and conclusions reported in this paper are those of the authors and are independent from the funding sources. No endorsement by the Ontario Brain Institute, ICES, the Ontario MOHLTC, or CIHI is intended or should be inferred. MKK and PCA are supported by Mid-Career Investigator Awards and RHS is supported by a Clinician-Scientist Phase II Award from the Heart and Stroke Foundation of Canada and holds a grant from the Ontario Brain Institute.

\section{CONFlicts of InTEREST}

The authors report no conflicts of interest.

\section{Statement of Authorship}

AYXY, LCM, PCA, MKK, RHS, and SEB conceived and designed the study. CD carried out the statistical analysis. AYXY and LCM drafted the manuscript. All authors contributed to the data interpretation and manuscript revision. All authors approve of the submitted manuscript.

\section{Supplementary Material}

To view supplementary material for this article, please visit https://doi.org/10.1017/cjn.2019.335

\section{REFERENCES}

1. Krueger H, Koot J, Hall RE, O'Callaghan C, Bayley M, Corbett D. Prevalence of individuals experiencing the effects of stroke in Canada: trends and projections. Stroke. 2015;46(8):2226-31.

2. Reeves MJ, Bushnell CD, Howard G, et al. Sex differences in stroke: epidemiology, clinical presentation, medical care, and outcomes. Lancet Neurol. 2008;7(10):915-26.

3. Kapral MK, Fang J, Hill MD, et al. Sex differences in stroke care and outcomes: results from the Registry of the Canadian Stroke Network. Stroke. 2005;36(4):809-14.
4. Gattringer T, Ferrari J, Knoflach M, et al. Sex-related differences of acute stroke unit care: results from the Austrian stroke unit registry. Stroke. 2014;45(6):1632-38.

5. Petrea RE, Beiser AS, Seshadri S, Kelly-Hayes M, Kase CS, Wolf PA. Gender differences in stroke incidence and poststroke disability in the Framingham heart study. Stroke. 2009;40(4):1032-37.

6. Lisabeth LD, Reeves MJ, Baek J, et al. Factors influencing sex differences in poststroke functional outcome. Stroke. 2015;46(3):860-63.

7. Phan HT, Reeves MJ, Blizzard CL, et al. Sex differences in severity of stroke in the INSTRUCT study: a meta-analysis of individual participant data. J Am Heart Assoc. 2019;8(1):e010235.

8. Katz SJ, Kabeto M, Langa KM. Gender disparities in the receipt of home care for elderly people with disability in the United States. JAMA. 2000;284(23):3022-27.

9. Blackburn J, Albright KC, Haley WE, et al. Men lacking a caregiver have greater risk of long-term nursing home placement after stroke. J Am Geriatr Soc. 2018;66(1):133-39.

10. Bushnell CD, Reeves MJ, Zhao X, et al. Sex differences in quality of life after ischemic stroke. Neurology. 2014;82(11):922-31.

11. Kokotailo RA, Hill MD. Coding of stroke and stroke risk factors using international classification of diseases, revisions 9 and 10 . Stroke. 2005;36(8):1776-81.

12. Juurlink D, Preyra C, Croxford R, et al. Canadian Institute for Health Information Discharge Abstract Database: A Validation Study Toronto: ICES; 2006. Available at: https://www.ices.on.ca/ publications/atlases-and-reports/2006/canadian-institute-for-healthinformation; Published June 2006; accessed August 19, 2006.

13. Morris JN, Fries BE, Morris SA. Scaling ADLs within the MDS. J Gerontol ABiol Sci Med Sci. 1999;54(11):M546-53.

14. Burrows AB, Morris JN, Simon SE, Hirdes JP, Phillips C. Development of a minimum data set-based depression rating scale for use in nursing homes. Age Ageing. 2000;29(2):165-72.

15. Hartmaier SL, Sloane PD, Guess HA, Koch GG, Mitchell CM, Phillips CD. Validation of the minimum data set cognitive performance scale: agreement with the mini-mental state examination. J Gerontol A Biol Sci Med Sci. 1995;50(2):M128-33.

16. Hirdes JP, Frijters DH, Teare GF. The MDS-CHESS scale: a new measure to predict mortality in institutionalized older people. J Am Geriatr Soc. 2003;51(1):96-100.

17. Maclagan LC, Maxwell CJ, Gandhi S, et al. Frailty and potentially inappropriate medication use at nursing home transition. J Am Geriatr Soc. 2017;65(10):2205-12.

18. Campitelli MA, Bronskill SE, Hogan DB, et al. The prevalence and health consequences of frailty in a population-based older home care cohort: a comparison of different measures. BMC Geriatr. 2016;16:133.

19. Austin PC. An introduction to propensity score methods for reducing the effects of confounding in observational studies. Multivariate Behav Res. 2011;46(3):399-424.

20. Austin PC. Optimal caliper widths for propensity-score matching when estimating differences in means and differences in proportions in observational studies. Pharm Stat. 2011;10(2):150-61.

21. Austin PC. Balance diagnostics for comparing the distribution of baseline covariates between treatment groups in propensity-score matched samples. Stat Med. 2009;28(25):3083-107.

22. Austin PC. The performance of different propensity score methods for estimating marginal hazard ratios. Stat Med. 2013;32(16):2837-49.

23. Jonsson AC, Ek J, Kremer C. Outcome of men and women after atrial fibrillation and stroke. Acta Neurol Scand. 2015;132(2):125-31.

24. Avgil Tsadok M, Jackevicius CA, Rahme E, Humphries KH, Pilote L. Sex differences in dabigatran use, safety, and effectiveness in a population-based cohort of patients with atrial fibrillation. Circ Cardiovasc Qual Outcomes. 2015;8(6):593-99.

25. Newman-Toker DE, Moy E, Valente E, Coffey R, Hines AL. Missed diagnosis of stroke in the emergency department: a cross-sectional analysis of a large population-based sample. Diagnosis (Berl). 2014;1(2):155-66.

26. Reeves M, Bhatt A, Jajou P, Brown M, Lisabeth L. Sex differences in the use of intravenous rt-PA thrombolysis treatment for acute ischemic stroke: a meta-analysis. Stroke. 2009;40(5):1743-49.

27. Reid JM, Dai D, Gubitz GJ, Kapral MK, Christian C, Phillips SJ. Gender differences in stroke examined in a 10-year cohort of 
patients admitted to a Canadian teaching hospital. Stroke. 2008;39(4):1090-95.

28. O'Donnell MJ, Diener HC, Sacco RL, Panju AA, Vinisko R, Yusuf S. Chronic pain syndromes after ischemic stroke: PRoFESS trial. Stroke. 2013;44(5):1238-43.

29. Park EY, Kim JH. An analysis of depressive symptoms in stroke survivors: verification of a moderating effect of demographic characteristics. BMC Psychiatry. 2017;17(1):132.

30. Delpont B, Blanc C, Osseby GV, Hervieu-Begue M, Giroud M, Bejot Y. Pain after stroke: a review. Rev Neurol. 2018;174(10):671-74.

31. Duffy SA, Jackson FC, Schim SM, Ronis DL, Fowler KE. Racial/ ethnic preferences, sex preferences, and perceived discrimination related to end-of-life care. J Am Geriatr Soc. 2006;54(1):150-57.
32. Buchanan RJ, Wang S, Ju H, Graber D. Analyses of gender differences in profiles of nursing home residents with Alzheimer's disease. Gender Med. 2004;1(1):48-59.

33. Luppa M, Luck T, Weyerer S, Konig HH, Riedel-Heller SG. Gender differences in predictors of nursing home placement in the elderly: a systematic review. Int Psychogeriatr. 2009;21(6): 1015-25.

34. Yu AY, Holodinsky JK, Zerna C, et al. Use and utility of administrative health data for stroke research and surveillance. Stroke. 2016;47(7):1946-52.

35. Sukul D, Hoffman GJ, Nuliyalu U, et al. Association between medicare policy reforms and changes in hospitalized medicare beneficiaries' severity of illness. JAMA. 2019;2(5):e193290. 